\title{
Analysis of the Distribution of Forest Management Areas by the Forest Environmental Tax in Ishikawa Prefecture, Japan
}

\author{
Yuta Uchiyama and Ryo Kohsaka \\ Kanazawa University Graduate School of Human and Socio-Environmental Studies, Kanazawa, Japan \\ Correspondence should be addressed to Yuta Uchiyama; yutanu4@yahoo.co.jp
}

Received 8 July 2016; Accepted 25 August 2016

Academic Editor: Kihachiro Kikuzawa

Copyright (c) 2016 Y. Uchiyama and R. Kohsaka. This is an open access article distributed under the Creative Commons Attribution License, which permits unrestricted use, distribution, and reproduction in any medium, provided the original work is properly cited.

\begin{abstract}
Forest management approaches vary according to the needs of individual municipalities with unique geographic conditions and local social contexts. Accordingly, there are two types of subsidies: a unified national subsidy and a prefecture-level subsidy, mainly from forest environmental taxes. The latter is a local tax. Our focus is on examining forest management using these two types of taxes (i.e., central and prefecture-level) and their correlations with social and natural environmental factors. In this paper, we examine the spatial distribution of management areas using subsidies from the central government, the Forestry Agency of Japan, and prefectural forest environmental taxes in Ishikawa. In concrete terms, the spatial correlations of the management areas under two tax schemes are compared with the natural hazard areas (as a natural environmental factor) and areas with high aging rates (as a social factor). The results are tested to see whether the correlations of areas with the two factors are significant, to examine whether the taxes are used for areas with natural and social needs. From the result, positive correlations are identified between the distribution of management areas and natural hazard areas and between the distribution of management areas and areas with high aging rates.
\end{abstract}

\section{Introduction}

Owing to the trend of the decreasing size of business in the Japanese forestry sector, the management of the forestland has involved serious reduction in forestry workers. Most parts of trees in forest plantations in Japan need to be harvested. Sustainable forest management issues, including tending and periodic thinning, need to be tackled over several generations. In mountainous forestlands and other forest areas that are difficult to access, most forest owners and forest associations are no longer able to maintain forestlands as their own businesses; forest management in those regions depends on support from national and regional governments.

The need for forest management differs among Japanese regions because their physical, geographical, and social contexts differ. Prefectures implement their forest policies in the context of their individual regions. The forest environmental tax is a policy option for sustainable management in individual prefectures. Forest management support from the prefectures depends on the general revenue resources of the prefectures. In addition to general revenue resources, revenue from the forest environmental tax in each prefecture is used for forest management. Kochi Prefecture introduced the first forest environmental tax in 2003, and 33 prefectures have now introduced the tax, not including urban prefectures such as Tokyo. Due to a shortage of revenue resources, it is necessary to use revenue resources effectively to deal with specific regional issues.

The forest environmental tax can be regarded as an institution of the Payment for Ecosystem Services (PES) [16]. To acknowledge the ecosystem services from forestlands sustainably, this tax has been introduced in the prefectures. The purpose of the tax is to implement forest management as a charge to the beneficiaries. In terms of PES, revenue from the forest environmental tax should be paid to forest owners and related people who maintain forests, to make them provide ecosystem services. In practice, revenues from the tax have been paid mainly to forest associations. The characteristics of the forest environment tax include the fact that the tax system is at a regional level, and beneficiaries in wider regions are required to pay relatively small amounts for the tax [7]. 
Because the tax system is at the prefecture level, prefectures are not necessarily uniform in their application of the system. A common feature of the forest environmental tax at the prefectural level is that taxpayers are frequently unaware of the tax, because of the limited amount (frequently 500 yen per annum) and the mode of payment (i.e., it is collected with the water usage fees or residence taxes). Almost all residents within the prefectures are obliged to pay these forest environmental taxes, except for certain urban prefectures such as Tokyo and Osaka, where they do not have such systems.

Because most taxpayers are unaware of their existence, the purpose and operations relating to the use of this tax money are not thoroughly examined from our perspectives based on GIS data. Are the taxes used in areas in urgent need of forest management, consistent with the scheme's original design? If so, which social or natural factors play a larger role?

As with many other public budget programs, management areas are distributed unevenly and without strict rules and standards. The areas are selected through negotiation between forest owners and forest cooperatives. Dialogues are critical because the main management areas under the forest environmental tax are artificial forests owned by private owners. The decisions of negotiations are outcomes of plans, lobbying, and prioritization. As a result, the decisions of management areas may be unequally distributed or even biased within a certain prefecture.

Other factors that may cause unequal distribution of management areas are the characteristics of forest cooperatives with different scales of budget and organizational structures. Negotiations between forest cooperatives and forest owners and budget sizes and organization structures of forest cooperatives are social factors that affect the distribution of forest management areas. Physical environmental factors of forest areas include the densities of trees, slopes, and accessibilities, such as existing roads. Because of these factors, the prefectures and municipalities have difficulty in implementing forest management equally in the forest area of each prefecture.

Under the influence of social and physical environmental factors, forest management areas under the forest environmental tax may be unevenly distributed. An evaluation of the use of the forest environmental tax is not conducted regarding the effective use of the tax for the whole area of a prefecture. The forest management areas that are selected by forest cooperatives in a bottom-up manner can be distributed in high risk areas of natural disaster or areas with high aging rates and few human resources for forestry.

When these areas do not overlap, there is a risk that forest management is implemented in areas that are not consistent with the goals of the introduction of the tax in each prefecture. Consequently, comparisons of the distribution of forest management areas by the tax and the distribution of high risk areas of natural disasters or population can contribute to evaluations of the effectiveness of the use of the tax.

The results of the comparative analysis can be used to examine the directions of forestry policies and the forest environmental tax. Even if it is difficult to evenly allocate

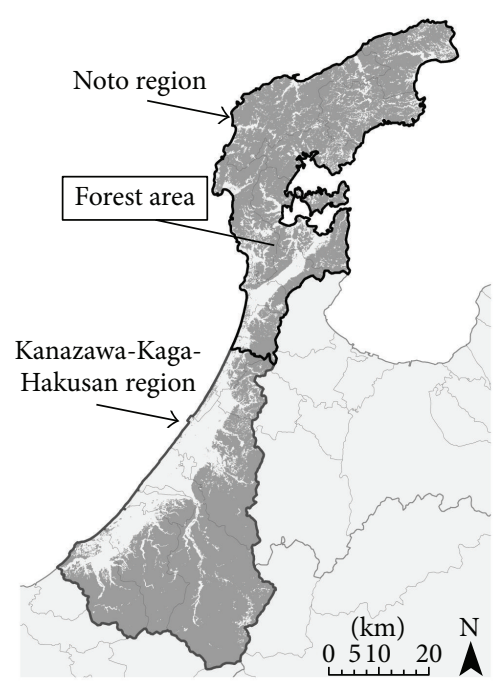

FIGURE 1: Distribution of forest areas in the Ishikawa prefecture.

forest management areas in a prefecture, management areas can be allocated in areas with a high risk of natural disaster or high aging rate and a lack of the required management. Forest management under the forest environmental tax needs to be implemented to sustainably acknowledge services from forestlands, to maximize such services, and to reduce the risk of natural hazard based on scientific evaluation of the use of the tax.

In this research, forest management areas under the forest environmental tax in Ishikawa prefecture are examined. The prefecture includes a peninsula, and mountainous areas are located in the north and southeast part of the prefecture (Figure 1). Forest area covers $73.7 \%$ of the land. In the forest area, the rate of coniferous forest is $47 \%$, and the rate of broadleaved forest is $53 \%$. Aging rates of the mountainous areas are relatively high, and those areas have few human resources in forestry. Through a comparative analysis of the distribution of forest management areas under the tax and distribution of high risk areas of natural hazards and older population, correlations of the distributions of the forest management areas and those specified areas are identified.

\section{Methodology}

2.1. Research Site and Forest Management Schemes. Since 2007, the forest environmental tax has been used in the Ishikawa prefecture, and forest management and educational activities have been implemented using revenue from the tax. Ishikawa has areas with different aging rates (Table 1), and the proportion of the population over 65 years of age in Noto region, located on the peninsula, is as high as 34\% (2010). Compared with the Kanazawa-Kaga-Hakusan region, where $21 \%$ of the population is over 65 of age, the elderly proportion of the Noto region is high. Areas with a high risk of natural hazards are almost the same between the former and latter regions. The proportion of forest areas in the Noto region is relatively high, but the difference in these rates is not large. 


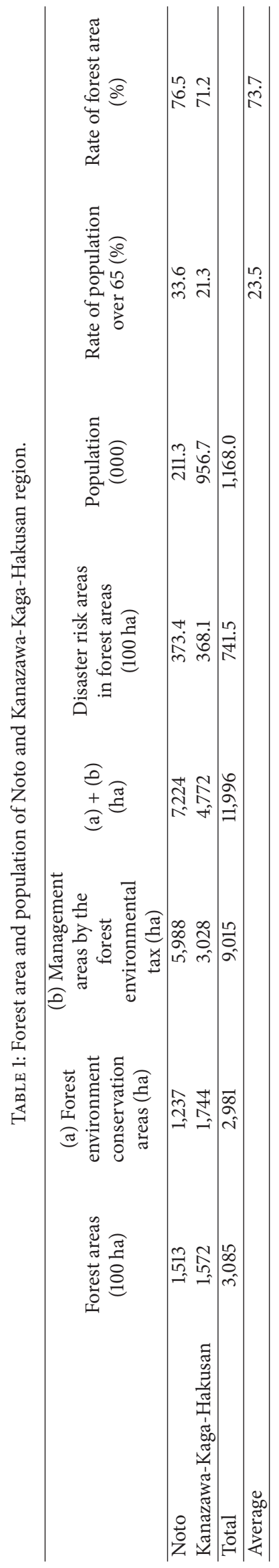


In the Ishikawa prefecture, there are two types of government supported forest management approaches (Table 2). One is forest environment conservation using subsidies from the central government (i.e., the Forestry Agency of Japan) and the other is forest management funded mainly by the forest environmental tax. The main aim of both types of management is conservation of the multiple functions of forests through revitalization of forestry in the prefecture, and management approaches, including development of roads for forestry, are implemented. The main operation of both types of management is the thinning of trees in the coniferous plantations. The purpose of thinning with high intensity in the management is the induction to mixed forest with broad-leaved trees in the abandoned coniferous plantations.

There are differences between the two types of management. For example, the aims of forest environment conservation operations include cost reduction of forestry, while the aims of forest management using the forest environmental tax include implementing management of disadvantaged forestlands. An example of a disadvantaged forestland is one with a steep gradient where the management cost is relatively high. The organizations primarily responsible for the former operations in the Ishikawa prefecture are the forestry cooperatives and other forestry organizations, and those responsible for the latter management are the forestry cooperatives. Regarding the required intensity of thinning, basically more than $20 \%$ of trees in the site are thinned in the forest environment conservation operations, while more than $40 \%$ of them are thinned in the forest management using the forest environmental tax. Selections of operations and management areas depend on the decision of the organizations. The prefecture does not select the areas that will be managed by the forestry cooperatives and other forestry organizations in a top-down manner. The management areas are selected based on a point in common between the two types of management.

2.2. Data. We apply the following four data sets for the analysis: (1) areas under forest management operations, (2) forest areas, (3) disaster risk areas, and (4) population age over 65 years. Explanations of the four data sets are given below.

2.2.1. Areas under Forest Management Operation. Data sets for areas under forest management operation were provided by Ishikawa prefecture [8] on the scale of the Oaza. The Oaza unit is a smaller administrative unit than a municipality. It can be regarded as a small-scale district in a municipality. The period was for five fiscal years (2008 to 2013) for forest environment conservation operations and six fiscal years for forest management by the forest environmental tax (2007 to 2013). We use the sum of the two schemes in individual fiscal years. The two schemes are added because in both schemes the decisions for area operations are made by local foresters or forest cooperatives in a bottom-up manner. In the analysis, we apply the polygon data provided by Zenrin Co. for all of the following analysis from forest areas and disaster risk areas at both the Oaza and municipality scale.

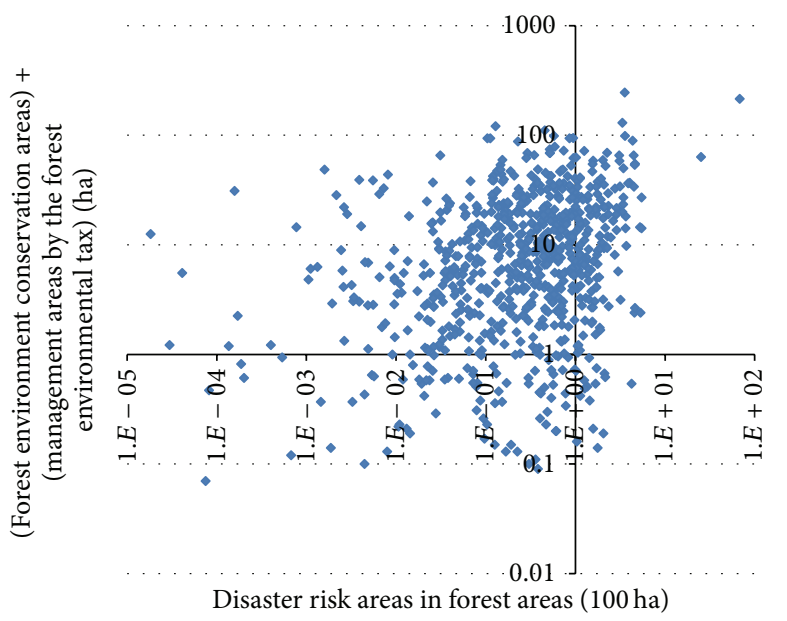

FIGURE 2: Correlation of government supported forest management areas and disaster risk areas (unit: microlevel Oaza).

2.2.2. Forest Areas. To analyze forest areas, the land use grid data provided by the Land, Infrastructure and Transportation Ministry (MLIT) [9] is used. The year of the data is 2009, and the grid resolution is $100 \mathrm{~m}$ square. Specifically, the grid data that has the land use category of "forest" is used as the data that shows the distribution of the forest areas. This data is used because it has relatively high grid resolution and it is possible to analyze correspondence with disaster risk areas in detail by aggregating the data in the Oaza unit. Aggregation of the data of forest areas is required to implement this analysis, because the forest areas of the Oaza unit are not disseminated in official statistical data sets.

2.2.3. Disaster Risk Areas. The data for disaster risk areas provided by the MLIT [10] is used. These polygon data show the distribution of areas at high risk for sediment disaster. The proportion of disaster risk area in each forest area of Oaza is calculated. The disaster risk areas are designated by prefecture, and the MLIT collects and disseminates data regarding the designated disaster risk areas.

2.2.4. Population Age over 65 Years. Census data for the year 2010 [11] are used in this analysis. The data is aggregated in the Oaza unit.

\section{Results and Discussion}

In this section, we review the results from the municipality and smaller microscale (with the unit of Oaza).

3.1. Results from Microscale. We capture the correlation of forest environment conservation operations and forest management areas with the forest environmental tax and disaster risk area. From the results, the areas with the two types of management have correlations of 0.43 with the disaster risks area, which is a relatively weak correlation (Figure 2).

When the individual management areas are examined, the correlation is 0.36 for forest environment conservation 


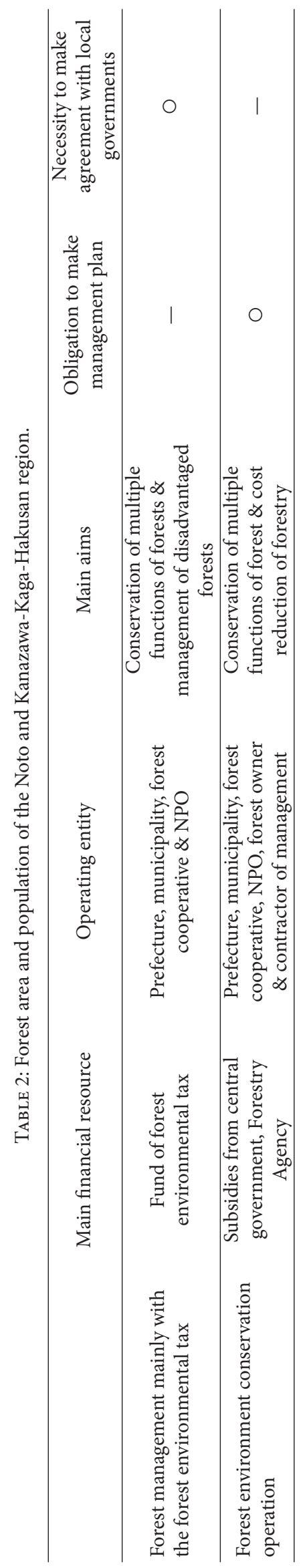




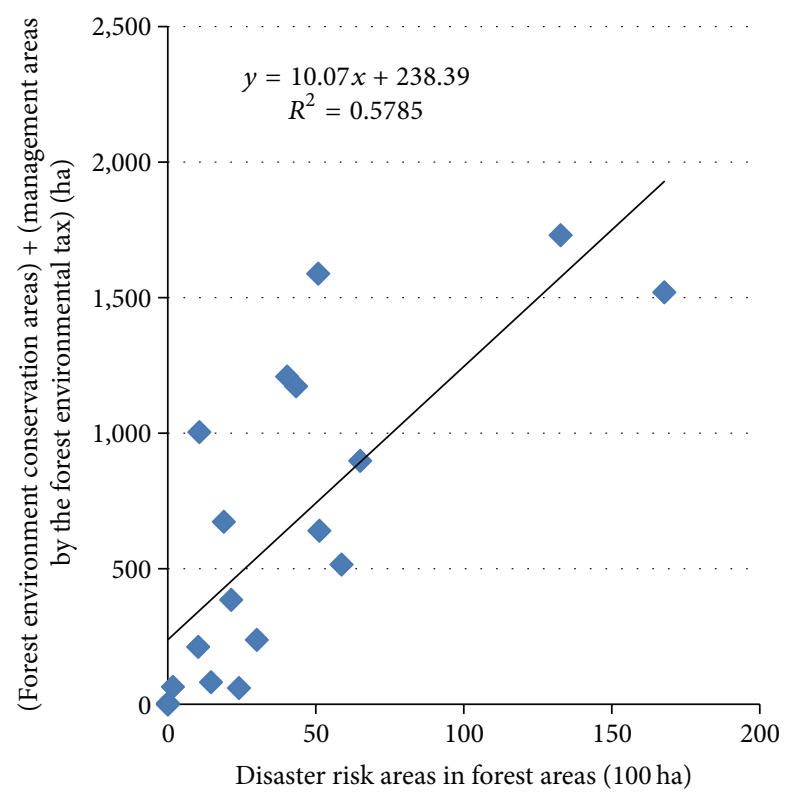

FIGURE 3: Correlation of government supported forest management areas and disaster risk areas (unit: municipality).

areas and 0.38 for forest management areas with the forest environmental tax. These correlation coefficients show that the two schemes selected different areas, resulting in a higher correlation of the total areas of both management areas with disaster risk areas.

In this research, we use the data of total forest areas. As the preliminary step, relationships between distribution of the two types of the management areas and forest areas are examined. The results show that the certain amount of forest management areas can be situated in individual Oaza that includes disaster risk areas. However, the main type of trees in individual Oaza is not considered because of the data limitation. In the future research, the main type of trees in individual Oaza will be detected by remotely sensed data with high resolution, and the detailed relationships between distribution of the two types of the management areas and forest areas with each type of trees in microlevel Oaza will be examined.

Next, we examine the ratio of forest areas with the two management schemes and their correlations with the proportion of residents over the age of 65 in each unit of Oaza. The resulting correlation is 0.16 . We examine the two schemes individually, but the results indicate lower correlations, below 0.16 . The results suggest weaker correlations with residents over the age of 65 in each unit of Oaza and the two schemes.

3.2. Results from Municipality Scale. We apply the same analysis with the same indicators to the scale of municipalities. The correlation with forest management areas under the two schemes with disaster risk areas was 0.76 , a high positive correlation (Figure 3). For the individual schemes, the correlation is 0.55 for forest environment conservation operations and 0.74 for forest management areas by the forest environmental tax. By capturing correlation of the disaster risk area with each management scheme, it becomes clear that stronger correlation is found with the forest management scheme. The results indicate that forest management areas correspond closely to disaster risk areas, which potentially contributes to the prevention of disaster or lowering of the risks.

In the analysis of the microscale, if Oaza has forest areas with disaster risk and neighboring Oaza have the forest management areas, those relationships of the Oaza cannot be reflected to the correlation between the distribution of the high risk areas of natural disasters and the management areas, even if those management areas can contribute to reduction of disaster risk in the Oaza. That is the cause of the stronger correlation in municipality level. The boundaries of municipalities based on the borders of watersheds and parts of the management areas in a municipality can be situated near the high risk areas of natural disasters, and those management areas are not precisely overlapped with the high risk areas but they can contribute to reduction of the disaster risk in the municipality.

In the following step, we examine the ratio of forest areas to the two management schemes and their correlations with the proportion of residents over the age of 65 in each unit of the municipality. The resulting correlation is 0.46 , which is a weaker correlation. We examine the areas of the two schemes individually, and the results indicate correlations of -0.14 for forest environment conservation operations and 0.63 for forest management areas with the forest environmental tax (Figure 4). The results suggest higher correlations with forest management areas and weaker correlations with forest environment conservation areas for residents over the age of 65 at the municipality level.

This result implies that forest management areas with the forest environmental tax were implemented with a relatively high concentration in areas with high proportions of the population over the age of 65 . The cause of the different correlations of the forest management areas by the tax and the forest environment conservation areas with the proportion of residents over the age of 65 can be related to the difference in the schemes of the two types of the management (Table 2). To implement the former management, making management plan is not needed so that the implementation of the management of disadvantaged forests in the areas with rack of human resources is easier. In addition, the latter management can be implemented in the areas with relatively proactive in forestry, because the aims of the latter management include cost reduction of forestry. In this respect, the latter management areas can be distributed in relatively advantaged areas in terms of social and natural conditions.

We will discuss the reason for larger correlations at the municipality level than at the microlevel of Oaza in Section 4.

\section{Discussion}

The results for the two schemes showed higher correlations at the municipality level than at the micro-Oaza level for residents over 65. Regarding disaster risk areas, correlations were found at both the micro-Oaza and municipality 

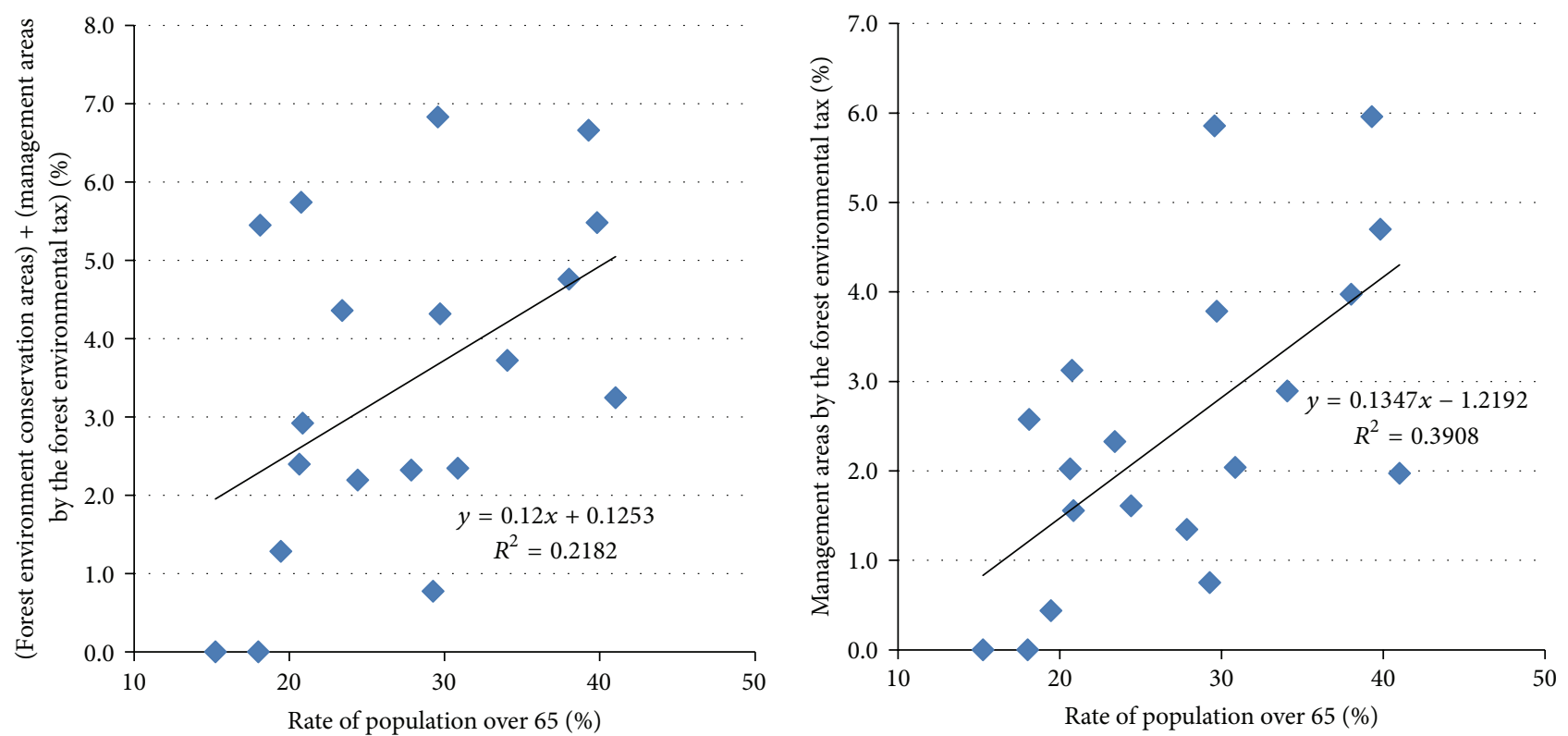

FIGURE 4: Correlation of the proportion of government supported forest management areas and the rate of population over 65 (unit: municipality).

levels. The correlations of both schemes with the disaster risk areas imply that bottom-up decisions in the selection of forest management areas mainly by the forest cooperatives were instrumental in managing areas for disaster prevention.

The municipality level may be the appropriate level to understand the correlation of the rate of forest management area with the rate of people who are related to forest management. Their places of residence often do not correspond to Oaza with the management areas on a oneto-one basis, but they do correspond to municipalities. To analyze the spatial correlation of the distribution of the human resources of forestry and the forest management area with the environmental tax, the municipality level may well be more appropriate than the Oaza level. In this paper, the correlation of the rate of people who are over 65 years with the rate of the forest management area was examined at the municipality level, and a relatively strong and positive correlation was identified.

As a general trend, it was noted that the forest environment management schemes were implemented for areas with a relatively high proportion of the population over 65 years; it is suggested that the scheme potentially contributed to areas with less workforce (and less economic activity) in forestry. In other words, the forest environment conservation scheme was conducted in areas with more social need, in addition to disaster risk areas that need disaster prevention.

\section{Future Research}

In future research, the specific selection processes for forest areas managed by forestry cooperatives need to be investigated. Through an understanding of these processes, methods to lead forest cooperatives to select appropriate areas that need management via the environmental tax can be identified. The variables (e.g., ratio of plantation area, tree types, decreasing ratio of population) that can be related to the distribution of the management areas will be identified based on that investigation and multivariate analysis. As mentioned in Section 3.1, types of trees in individual management area need to be considered in the future research. To overcome the limitation of the data of forest area with different type of trees, the analysis to detect the tree types in the management areas by using remotely sensed data with high resolution will be implemented.

Local governments are required to manage forestry cooperatives to effectively use revenue from the forest environmental tax, and they need to know the conditions for appropriate selection of forest cooperatives in management areas.

\section{Competing Interests}

The authors declare that there are no competing interests regarding the publication of this paper.

\section{Acknowledgments}

This work was supported by the MEXT, KAKENHI [26360062, 15H01597]; Environment Research and Technology Development Fund [1-1303, S-15-2(3)]; Research Institute for Humanity and Nature; Obayashi Foundation; Heiwa Nakajima Foundation; Kurita Water and Environment Foundation; and the Education and Research Base regarding the Ionic Liquid in the Satoyama Biomass Refinery. Thanks are extended to Mr. Shinichi Amada and Dr. Jun Fukuda at the Forest Agency of Japan and Mr. Yuho Hifumi and 
Mr. Shota Kimoto at the forest management division of the Ishikawa prefecture.

\section{References}

[1] S. Engel, S. Pagiola, and S. Wunder, "Designing payments for environmental services in theory and practice: an overview of the issues," Ecological Economics, vol. 65, no. 4, pp. 663-674, 2008.

[2] S. Wunder, S. Engel, and S. Pagiola, "Taking stock: a comparative analysis of payments for environmental services programs in developed and developing countries," Ecological Economics, vol. 65 , no. 4, pp. 834-852, 2008.

[3] M. Sakagami and K. Kuriyama, Values of Ecosystem Services: Economical Evaluation, Koyo-Shobo, Kyoto, Japan, 2009 (Japanese).

[4] K. H. Redford and W. M. Adams, "Payment for ecosystem services and the challenge of saving nature," Conservation Biology, vol. 23, no. 4, pp. 785-787, 2009.

[5] R. Muradian, M. Arsel, L. Pellegrini et al., "Payments for ecosystem services and the fatal attraction of win-win solutions," Conservation Letters, vol. 6, no. 4, pp. 274-279, 2013.

[6] S. Schomers and B. Matzdorf, "Payments for ecosystem services: a review and comparison of developing and industrialized countries," Ecosystem Services, vol. 6, pp. 16-30, 2013.

[7] L. Bespyatko and H. Imura, "Investigation on environmental tax for forestry in Japan as a scheme of payments for environmental services," Environmental Science, vol. 21, no. 2, pp. 115-132, 2008 (Japanese).

[8] Ishikawa Prefecture, "Areas of forest environment conservation operations and forest management by the forest environmental tax," 2015.

[9] Land, Infrastructure, and Transportation Ministry (MLIT), Land use distribution, 2016, http://nlftp.mlit.go.jp/ksj/gml/datalist/ KsjTmplt-L03-b.html.

[10] Land and Infrastructure and Transportation Ministry (MLIT), "Disaster risk areas," 2016, http://nlftp.mlit.go.jp/ksj/gml/datalist/ KsjTmplt-A26.html.

[11] Statistics Bureau of Japan, Census data for the year 2010, 2016, http://www.stat.go.jp/data/kokusei/2010/. 

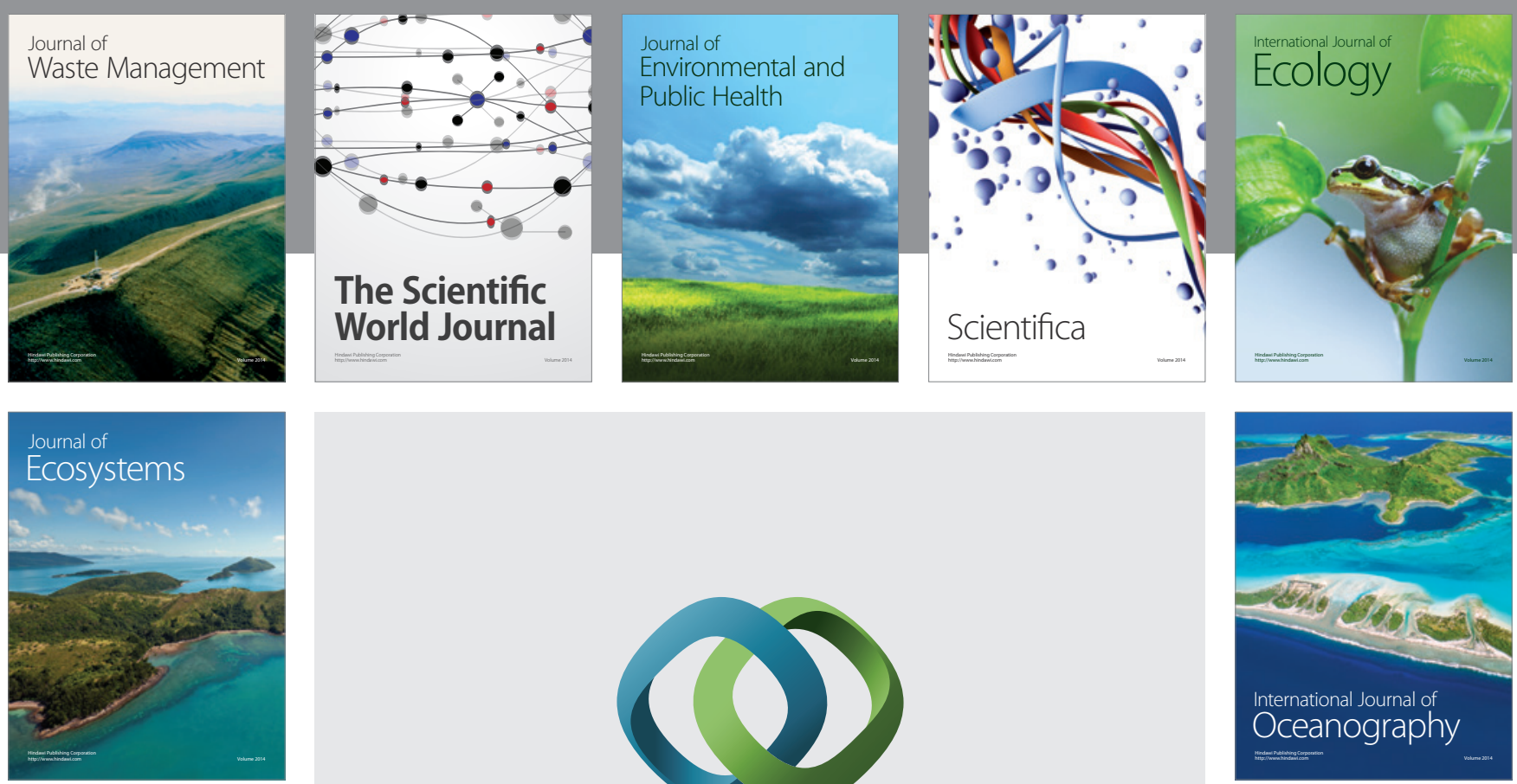

The Scientific World Journal
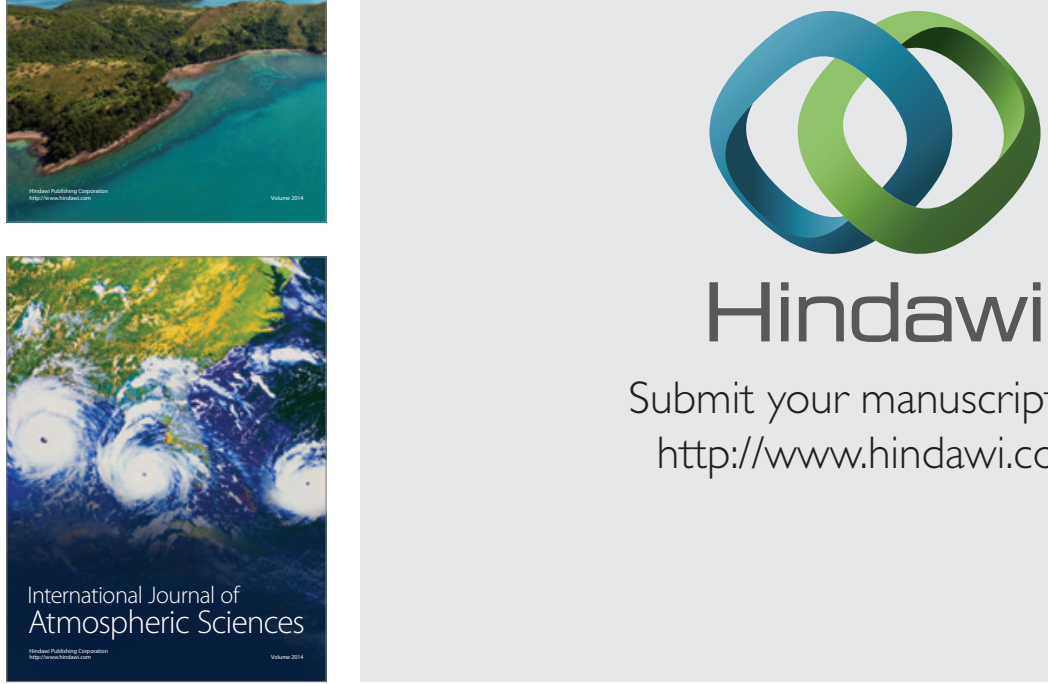

\section{Hindawi}

Submit your manuscripts at

http://www.hindawi.com
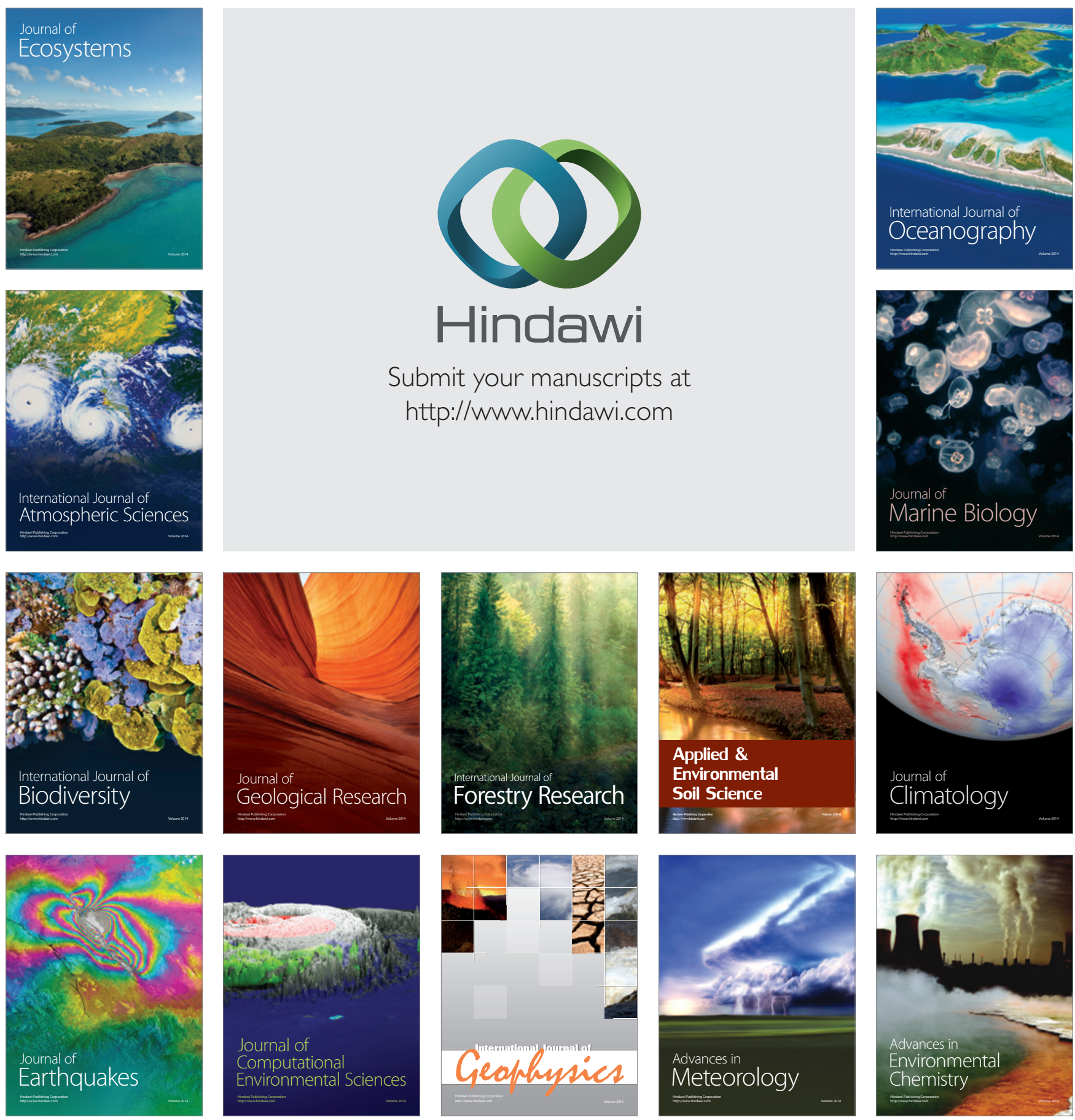